\title{
COMPORTAMENTO DE DIFERENTES CULTIVARES DE MORANGUEIRO NA PRODUÇÃO DE MUDAS DE CAMPO
}

\author{
LUIS ENRIQUE ROBLEDO ORTIGOZA \\ Engenheiro Agrônomo
}

Orientador: Prof. Dr. JOÃO TESSARIOLI NETO

Dissertação apresentada à Escola Superior de Agricultura "Luiz de Queiroz", Universidade de São Paulo, para a obtenção do título de Mestre em Agronomia, Área de Concentração: Fitotecnia.

\author{
PIRACICABA \\ Estado de São Paulo - Brasil \\ Novembro - 1999
}




\title{
Dedos Intemacionais de Catalogação na Publicação (CP) DMSÃODEBBLOTECAEDOCUMENTAÇÄO-Campes Liz de QueirożUSP
}

\author{
Robledo Ortigoza, Luis Enrique \\ Comportamento de diferentes cultivares de morangueiro na produção de mudas \\ de campo/ Luis Enrique Robledo Ortigoza. - - Piracicaba, 1999. 43 p. \\ Dissertação (mestrado) - - Escola Superior de Agricultura Lujz de Queiroz, 1999. \\ Bibliografia. \\ 1. Estolho 2. Morango 3. Muda frutífera 4. Produção vegetal 5. Variedade I. Titulo
}

CDD 634.75

"Permitida a cópia total ou parcial deste documento, desde que citada a fonte - 0 Autor" 
Aos meus pais, com afeto,

Por todo carinho, amor e compreensão

Ao longo de toda minha vida.

Ofereço.

A minha esposa Marisa e meu filho Ivan 


\section{AGRADECIMIENTOS}

À Deus, pela fé e perseverança concedidas em todos os momentos.

À Escola Superior de Agricultura "Luiz de Queiroz", pela oportunidade concedida para realização deste curso.

Ao Prof. Dr. João Tessarioli Neto, pela orientação, apoio e amizade durante os momentos necessários.

Aos Professores do Departamento de Produção Vegetal, especialmente ao Professor Salim Simão, pelo apoio prestado durante o curso.

Aos colegas e amigos Ricardo Kluge, Paulo S. R. de Araújo pela troca de idéias, apoio e colaboração na parte final da dissertação.

Aos amigos Valéria Modolo, Shoey Kanashiro, Walter G. Rodrigues R., Inácio de Barros, por sua valiosa colaboração no decorrer do experimento.

Aos amigos Angelo Jacomino, Nilton M. Costa, Patrícia Gomes, Regma, Gilson Rezende ( $\mathbf{\uparrow}$ ), pela troca de idéias, discussões sobre temas profissionais e pessoais que muito auxiliaram na minha formação.

Aos amigos Juan S. Delgado R. e Osvaldo R. Peralta H., pela convivência, confiança e amizade, durante todo momento. 
Aos Funcionários do Departamento de Produção Vegetal da ESALQ, pelo apoio e amizade.

Aos Funcionários da Biblioteca Central da ESALQ, especialmente a Kátia, pela colaboração das referências e na busca do material bibliográfico.

Enfim, a todos que, direta ou indiretamente, contribuíram para que vencesse o desafio empreendido. 


\section{SUMÁRIO}

Página.

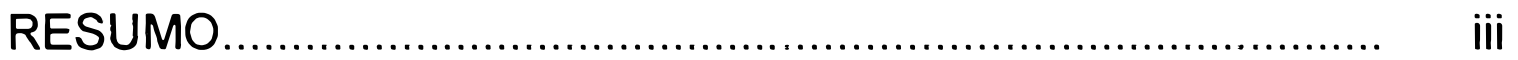

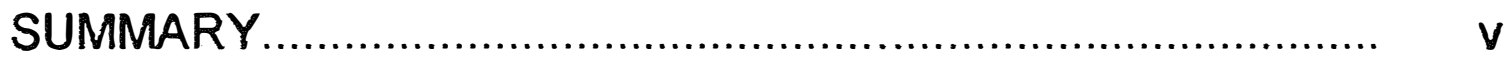

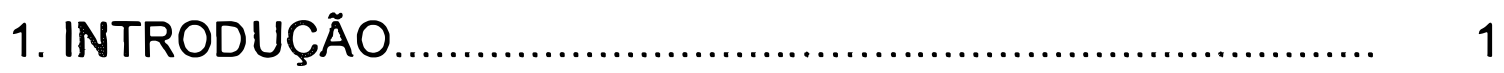

2. REVISÃO DE LITERATURA............................................

2.1. Origem e Distribuição Geográfica..................................... 3

2.2. Classificação Botânica..................................................... 4

2.3. Descrição Botânica............................................................. 4

2.4. Cultivares explorados no Brasil......................................... 6

2.5. Propagação vegetativa e produção de mudas...................... 7

2.6. Efeito dos fatores ecológicos na produção de mudas.......... 9

3. MATERIAL E MÉTODOS ............................................... 11

3.1. Local, clima e período de experimentação........................... 11

3.2. Caracterização do local................................................... 13

3.3. Cultivares estudadas..................................................... 15

3.4. Plantio das matrizes e condução......................................... 16

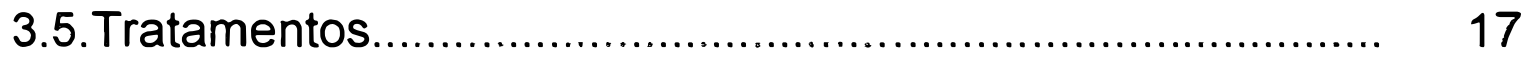

3.6. Delineamento experimental............................................ 18

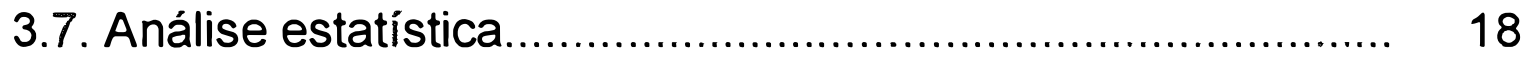

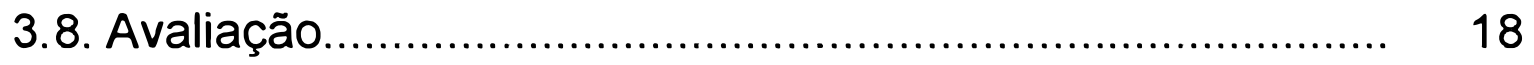


4. RESULTADOS E DISCUSSÃO...................................... 21

5. CONSIDERAÇÕES GERAIS ........................................ 30

6. CONCLUSỎES ....................................................... 31

REFERÊNCIAS BIBLIOGRÁFICAS................................. 32

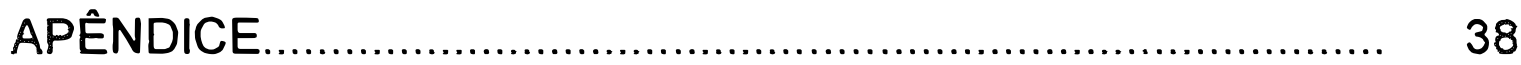




\title{
COMPORTAMENTO DE DIFERENTES CULTIVARES DE MORANGUEIRO NA PRODUÇÃO DE MUDAS DE CAMPO
}

\author{
Autor : LUIS ENRIQUE ROBLEDO ORTIGOZA \\ Orientador : Prof. Dr. JOÃO TESSARIOLI NETO
}

\section{RESUMO}

O objetivo deste trabalho foi avaliar o comportamento de sete cultivares de morangueiro na fase de produção de mudas, em duas épocas, sob condições de campo. O experimento foi efetuado no Departamento de Produção Vegetal da Escola Superior de Agricultura "Luiz de Queiroz", em Piracicaba-SP.

Empregou-se 0 delineamento experimental de blocos completamente casualizados, com 14 tratamentos e 4 repetições através de um esquema fatorial de $7 \times 2$. Os fatores estudados foram cultivares (Campinas IAC-2712, IAC Princesa Isabel, Chandler, Dover, Pajaro, Toyonoka e Korona) e épocas de coleta das mudas (14/03/1997; 15/04/1997).

Determinou-se a quantidade de mudas produzidas por metro quadrado e a classificação das mudas em quatro categorias: Extra, Primeira, Segunda e Descarte.

Houve diferenças quanto a quantidade de mudas de morangueiro produzidas por metro quadrado, de acordo com a cultivar. As cultivares Dover e Campinas produziram maior quantidade de mudas do que as cultivares Korona, Chandler, Princesa Isabel, Toyonoka e Pajaro, independente da época de coleta. 
A coleta de mudas na segunda época (15/04/97) proporcionou a obteção de mudas de qualidade superior à observada na primeira época (14/03/97), independente da cultivar. 


\title{
EVALUATION OF STRAWBERRY (Fragaria $x$ ananassa) CULTIVARS IN THE PRODUCTION OF SEEDLING UNDER FIELD CONDITIONS
}

\author{
Author: LUIS ENRIQUE ROBLEDO ORTIGOZA \\ Adviser : Prof. Dr. JOÃO TESSARIOLI NETO
}

\section{SUMMARY}

The aim of this research was the evaluation of seven strawberry cultivars in the stage of seedling production, during two different collection dates under field conditions.

The experiment was conducted at the Departament of Vegetal Production of the Escola Superior de Agricultura "Luiz de Queiroz", Piracicaba-SP.

The experimental design was of completely randomised plot with 14 treatments and 4 repetitions with the factorial scheme of $7 \times 2$. The variables were the cultivars (Campinas IAC-2712, IAC Princesa Isabel, Chandler, Dover, Pajaro, Toyonoka and Korona) and the date of seedling collection (14/03/1997; 15/04/1997).

The seedling were considered according to four categories: Extra, First, Second, Discarded and the number produced in one square metre. 
Significance difference were shown in the number of seedling produced in one square metre in different cultivars. Dover and Campinas produced higher number of seedlings compared to cultivars Korona, Chandler, Princesa Isabel, Toyonoka and Pajaro, independenthy to the date of collection.

The quality of seedling collected on the second date (15/04/1997) was superior to the ones collected on the first date (14/03/1997) independently to the cultivar. 


\section{INTRODUÇÃO}

O morangueiro é considerado um dos mais importantes cultivos de "pequenos frutos" dentro da Horticultura, sendo produzido em várias regiões de clima ameno. Seus frutos possuem aparência atrativa, sabor agradável e alto teor em ácido ascórbico (vitamina C).

A exploração racional do morangueiro é relativamente recente, iniciandose a partir do século XIX. As cultivares existentes em nossos dias são produtos da civilização, obtidas através de hibridações e seleções (Miquelão, 1994). O morangueiro cultivado (Fragaria X Ananassa Duch) foi obtido do cruzamento entre as espécies Fragaria chiloensis, Fragaria virginiana e Fragaria ovalis, todas oriundas do continente americano (Passos, 1986).

Os Estados Unidos, com a produção anual de $738.000 \mathrm{t}$, é o maior produtor mundial, seguido da Espanha (236.000 t), Japão (202.000 t), Coréia (174.000 t), Itália (150.000 t) e Polônia (141.602 t). Entre os paises da América do Sul, destacam-se o Chile (16.000 t) e a Colômbia (15.000 t) (FAO, 1997).

Segundo o Instituto de Economia Agrícola (1997), o Brasil produz, aproximadamente, $50.000 \mathrm{t}$ anuais de morango. Dentre $\mathrm{o}$ estados brasileiros, destaca-se São Paulo, com $80 \%$ da produção nacional (Secretaria da Agricultura e Abastecimento de São Paulo, 1996).

O cultivo do morangueiro em escala comercial no Estado de São Paulo desenvolveu-se rapidamente nas últimas décadas, devido a vários fatores, entre eles a utilização de cultivares melhoradas, o emprego de novas técnicas 
de cultivo, o aumento na procura de frutos pelas agroindústrias e a expansão da cultura para novas áreas (Miquelão, 1994).

A produção comercial de frutos de morango tem sido estudada e acompanhada por vários autores, entretanto, a produção de mudas tem recebido pequena atenção.

Deste modo, para se ter maiores informações sobre a produção quantitativa e qualitativa de mudas de estolhos de morangueiro, avaliou-se o comportamento de sete cultivares de morangueiro em duas épocas de coleta das mudas. 


\section{REVISÃO DE LITERATURA}

\subsection{Origem e Distribuição Geográfica}

O morangueiro (Fragaria $\mathrm{x}$ ananassa) é um híbrido de duas espécies: $F$. chiloensis (L.) Duch. e F. virginiana Duch. Alguns cultivares existentes também são derivados da hibridação entre $F$. ovalis (Lehn.) Rydb com as duas espécies anteriormente citadas (Galleta \& Bringhurst, 1990). A hibridação de $F$. chiloensis e $F$. virginiana ocorreu espontaneamente na Europa, por volta de 1700 , quando plantas femininas de $F$. chiloensis, de origem chilena, cresceram nas proximidades de plantas masculinas de F. virginiana, de origem norteamericana (Larson, 1994).

Embora desenvolvam-se melhor em regiōes mais frias, os morangueiros podem se desenvolver bem em clima quente e seco (Steinberg, 1988). No Brasil, o morangueiro se adaptou bem desde o sul de Minas Gerais até o Rio Grande do Sul (Santos, 1993). 


\subsection{Classificação Botânica}

O morangueiro cultivado pode ser classificado de acordo com Engler (1954) ou Cronquist (1981), conforme a descrição abaixo:

\begin{tabular}{lll}
\hline & Engler & Cronquist \\
\hline Divisão & Angiospermae & Magnoliophyta \\
Classe & Dicotyledoneae & Magnoliopsida \\
Subclasse & Archichlamydeae & Rosidae \\
Ordem & Rosales & Rosales \\
Família & Rosaceae & Rosaceae \\
Gênero & Fragaria & Fragaria \\
Espécie & Fragaria x ananassa & Fragaria x ananassa \\
\hline
\end{tabular}

\subsection{Descrição Botânica}

O morangueiro é uma planta herbácea, perene e rasteira. Cresce na forma de pequenas touceiras e, mesmo considerada perene, ela é cultivada como uma cultura anual (Filgueira, 1982).

O sistema radicular do morangueiro é fasciculado e superficial, sendo que 85 a 90\% das raízes (avaliação em peso seco) são encontradas nos primeiros 10 centímetros de profundidade (Inforzato \& Camargo, 1973).

A parte central da planta recebe a denominação de coroa e é formada por entrenós bem curtos e circundada por estípulas.

As folhas são compostas, trifolioladas, com um folíolo mediano e dois laterais, apresentando estípulas na base do pecíolo (Galleta \& Bringhurst, 1990; Queiroz-Voltran et al., 1996). As gemas são formadas nas axilas das folhas e podem dar origem aos estolões, também denominados estolhos, ou às inflorescências. Os estolões são caules prostrados que possuem entrenós maiores quando comparados à coroa, geralmente em número de dois, nos 
quais se desenvolvem as raízes e as folhas do novo perfilho (Galleta \& Bringhurst, 1990).

As flores possuem pétalas brancas reunidas em inflorescências do tipo rácimo. As cultivares comerciais produzem flores completas e autoférteis. Entretanto, há a ocorrência de protoginia e, conseqüentemente, a possibilidade de ocorrer cruzamentos naturais, geralmente através de insetos. A taxa de alogamia é variável e muito dependente da população de insetos (Groppo \& Tessarioli Neto, 1991).

As flores de morangueiro da maioria das cultivares são geralmente hermafroditas, também chamadas perfeitas, pois possuem órgãos sexuais masculinos e femininos. Existem ainda algumas cultivares pseudohermafroditas que, mesmo possuindo órgãos femininos e masculinos, têm estes últimos atrofiados e produzem pólen estéril. Existem também cultivares chamados unissexuais, que possuem apenas órgãos femininos, sendo esta característica encontrada especialmente em cultivares espontâneas e, para que a flor seja fecundada e produza frutos, é necessário que sejam polinizadas com pólen de outras cultivares que tenham os órgãos masculinos desenvolvidos e férteis. Entretanto, de maneira geral e em todas as cultivares, as inflorescências possuem número variável de flores, atingindo muitas vezes grande quantidade delas. Estas inflorescências se formam a partir de gemas existentes nas axilas das folhas, sendo que a primeira flor que desabrocha é aquela que dará origem ao primeiro fruto, sendo a mais desenvolvida aquela que se encontra na extremidade da inflorescência (Padovani, 1991).

A parte comestível, carnosa e suculenta do morango é, na verdade, o receptáculo hipertrofiado da flor, onde estão inseridos os verdadeiros frutos (Coombe, 1976). Estes são representados pelos pontos escuros que aparecem aderidos à epiderme da polpa do morango, botanicamente denominados aquênios e muitas vezes confundidos com sementes. Os aquênios são de vital importância para o crescimento do fruto, pois são fontes de hormônios de crescimento (Groppo et al., 1997). 


\subsection{Cultivares exploradas no Brasil}

As cultivares mais plantadas no Brasil são Campinas IAC-2712, Dover, Reiko, Chandler, IAC Princesa Isabel, consideradas como cultivares de mesa. Como cultivares para industrialização temos a IAC Guarani e a KonvoyCascata, sendo esta última muito explorada no Rio Grande do Sul. Todas essas cultivares são consideradas de dias curtos ou sensiveis ao fotoperíodo. Nos últimos anos têm sido introduzidas cultivares como Toyonoka, Korona, Oso Grande e outras, as quais estão sendo plantadas e testadas nas regiões produtoras (Groppo et al., 1997).

De acordo com Rebelo \& Balardin (1993), para se escolher uma cultivar para consumo "in natura" os seguintes aspectos devem ser levados em conta:

. Propagação: a cultivar a ser plantada deve ter facilidade de propagação, sem excessiva formação de estolhos, o que dificulta a formação de mudas vigorosas;

. Sanidade: devem ser usadas mudas sadias e livres de vírus;

- Resistência a doenças: as variedades devem ser resistentes principalmente a mancha de micosfarela e podridões que podem afetar as plantas e os frutos;

. Floração: deve ser reflorescente, de flores completas e grandes;

Frutificação: os frutos devem estar localizados fora da cobertura foliar, o que favorece a melhor coloração, tamanho grande e uniforme, e melhor qualidade organoléptica;

. Precocidade: é desejável que a cultivar produza o mais cedo possível;

. Produtividade: a produção por planta da cultivar escolhida nunca deve ser inferior a $\mathbf{3 0 0}$ gramas de frutos por ciclo.

Para as cultivares destinadas à industrialização, os frutos devem apresentar tamanho médio, formato cônico ou arredondado, coloração vermelho vivo, polpa vermelha e firme, aquênios pequenos e pouco numerosos, e cálice facilmente separável do fruto. 
Em virtude do morangueiro ser muito sensivel às variações climáticas, as cultivares costumam apresentar características diferentes, dependendo da região em que são cultivadas. Uma cultivar que em sua região de origem é mais produtiva e resistente a doenças pode produzir menos ou ser mais suscetivel aos fungos em outras regiões, que, por exemplo, possuam clima mais úmido.

Rice Junior (1990) testou cultivares de morango no Zimbabwe e observou que as cultivares californianas Tioga, Chandler e Rolinda foram as que melhor se adaptaram. Este autor comenta que o cultivo do morango nos trópicos é mais complexo pela interação entre cultivar, fotoperíodo e temperatura, que interfere significativamente na produção de mudas e frutos.

\subsection{Propagação vegetativa e produção de mudas}

Comercialmente, o morangueiro de dias curtos ou insensivel ao fotoperíodo é propagado vegetativamente através de mudas de estolhos.

A produção de mudas deve constituir uma atividade distinta da produção de frutos, iniciando com a produção de matrizes em ambiente protegido e a multiplicação posterior das matrizes em campo aberto. Esta deve ser feita em terrenos de meia encosta, com isolamento de pelo menos 300 metros de campos de produção de frutos, para se evitar a contaminação por vírus e a infestação de pragas (Passos et al., 1998).

Normalmente, utiliza-se glebas em pousio, cultivadas com leguminosas ou gramíneas por 2 anos ou mais, para reduzir os possiveis patógenos de solo. É desejável viveristas especializados, registrados e fiscalizados pela Secretaria de Agricultura e Abastecimento do Estado de São Paulo, produzem a maior parte das mudas consumidas neste estado, contudo, muitos produtores de frutos ainda produzem suas próprias mudas.

O Instituto Agronômico de Campinas vem fornecendo matrizes básicas de morangueiro, indexadas para vírus, desde 1967. Cooperativas, produtores particulares e empresas privadas, algumas utilizando micropropagação in vitro, 
também vêm produzindo matrizes (Passos et al.,1998). A partir dessas matrizes são produzidas um número variável de mudas em condição de campo, geralmente entre 100-150 mudas $/ \mathrm{m}^{2}$, que estarão aptas para transplantio nos meses de janeiro a março, dependendo da região e das condições de cultivo (Groppo \& Tessarioli, 1991).

Nas condições da região de Caacupé no Paraguay, segundo Alvarez et al. (1998), de um modo geral, a produção de mudas por planta matriz pode variar de 250 a 400 mudas. O aproveitamento de $80 \%$ é considerado satisfatório, desde que o viveiro seja conduzido com critérios técnicos.

As mudas são comercializadas com raiz nua e plantadas diretamente nos canteiros para a produção de frutos (Passos et al.,1998).

Segundo Betti ${ }^{1}$, existem cultivares com alta taxa de produção de mudas como IAC Campinas, IAC Guarani, Chandler e Dover, e também cultivares com taxa de multiplicação menor, como Toyonoka e Fern.

De acordo com Rodriguez (1997), a quantidade de mudas produzidas varia entre 350.000 e 400.000 mudas por hectare, ou 35 a 40 mudas $/ \mathrm{m}^{2}$, quantidade essa que não deve ser excedida, pois faz com que a qualidade da muda seja baixa, devido a diminuição do tamanho da coroa.

Em trabalho realizado por Cárdenas-Navarro et al. (1992), na região do Michoacan no México, foi verificado diferente comportamento na propagação das cultivares Tioga, Fern, CP-84-S, Douglas, Chandler, Parker e Ena, sendo que algumas cultivares, como Tioga e Douglas, apresentaram maior taxa de multiplicação, enquanto que a cultivar Ena emitiu menor número de mudas.

Türemis et al. (1997), comparando sete cultivares de morangueiro na produção de mudas de primeira e segunda categoria, observaram que as cultivares que obtiveram o maior número de mudas classificadas na primeira categoria apresentaram o menor número na segunda categoria, e assim

${ }^{1} \mathrm{BETTI}, \mathrm{J}$. A. (Instituto Agronômico de Campinas - Centro de Fitossanidade) Comunicação pessoal, 1998. 
inversamente, dependendo das cultivares. Segundo os autores, existe uma correlação negativa entre a qualidade de muda e o número de mudas por $\mathrm{m}^{2}$.

\subsection{Efeitos dos fatores edafoclimáticos na produção de mudas}

As cultivares de morangueiro geralmente diferem em seus requerimentos edafoclimáticos, podendo ou não se adaptar em algumas regiões, razão pela qual, nos EUA, se tem um grande número de estações experimentais envolvidas com o estudo desta cultura.

O crescimento e o desenvolvimento do morangueiro são altamente sensiveis das variações de temperatura do ar e do solo, além de serem dependentes da cultivar (Larson, 1994).

Na maioria das cultivares de morangueiro, a formação de estolhos está relacionada com o comprimento do dia, sendo necessário em geral, de 12 a 14 horas de luz para que seja iniciado o referido. De fato, a luz é um importante fator ambiental que regula o crescimento e o desenvolvimento do morangueiro. $O$ incremento no nivel de radiação resulta, normalmente, em aumento no peso da matéria seca da coroa, raiz e folha, na fixação e tamanho dos frutos e na formação e peso da matéria seca dos estolões (Larson, 1994).

Segundo Galleta \& Bringhurst (1990), a produção de estolões é favorecida por altas temperaturas, associadas aos dias longos. A maior ou menor produção de estolhos depende da cultivar (Cunha, 1976) e das condições ambientais. Em geral, o número de estolhos aumenta com a elevação da temperatura. De acordo com Passos (1986), para as cultivares utilizadas no Brasil a temperatura parece exercer maior influência do que o fotoperíodo. A interrupção na emissão de inflorescências ocorre se a temperatura se elevar, mesmo durante o inverno, época com fotoperíodo favorável ao desenvolvimento floral. Se a condição de temperatura elevada persistir até maio, conseqüentemente, ocorre a emissão de estolões. Entretanto, nos cultivares estudados por Dennis et al. (1970), a temperatura 
noturna não afetou a produção de estolões ou de flores, uma vez que esta foi influenciada, principalmente, pelo fotoperiodo.

Segundo Camargo (1973), o plantio do morangueiro deve ser realizado quando houver mudas vigorosas, bem enraizadas, sendo que a época deve ser determinada pela cultivar e pelas condições climáticas da região de cultivo.

Nas condições da Argentina, o número de estolhos varia de acordo com as caraterísticas ecológicas do lugar, o sistema de cultivo e as cultivares. Tem sido relatado que as cultivares, como Florida 90 e Tioga emitem muitos estolhos, enquanto que as cultivares Senga Sengana, Sunrise e Red Coat produzem menor número de estolhos. É também reportado que a emissão de estolhos pode ser estimulada com a eliminação periódica de todos os botões florais e com aplicação de regulador vegetal (ácido giberélico a $200 \mathrm{mg} . \mathrm{L}^{-1}$, em três aplicações) durante as três primeiras semanas depois do transplante das matrizes (Rodriguez, 1997).

luchi (1993) desenvolveu experimentos em condições de casa de vegetação e céu aberto, em Viçosa (MG) e observou que o aumento da temperatura e do fotoperiodo no verão diminuiu o florescimento do morangueiro, mas favoreceu a emissão de estolhos.

A emissão de estolhos pela planta-matriz é influenciada pela época de plantio. Segundo Webb \& White (1971) os plantios precoces atrasam a emissão de mudas.

Hersketh et al. (1990), trabalhando com as cultivares Rainier, Shuksan, Sumas e Totem, nas condições de cultivo comercial no Canadá observou que as maiores contribuições para a variação no número total de estolhos produzidos por metro quadrado foram, em ordem de importância, o efeito das condições climáticas do ano, cultivar e o espaçamento empregado. 


\section{MATERIAL E MÉTODOS}

\subsection{Local, clima e período de experimentação}

O experimento foi conduzido na área experimental do Departamento de Produção Vegetal da Escola Superior de Agricultura "Luiz de Queiroz", em Piracicaba - SP, situada a latitude $22^{\circ} 43^{\prime}$ Sul, longitude $47^{\circ} 38^{\prime}$ Oeste e altitude de 540 m, no período de Outubro de 1996 a Abril de 1997.

Segundo a classificação de Köppen, o clima da região é Cwa: tropical úmido, com três meses mais secos (jun/jul/ago), chuva de verão e seca no inverno, temperatura média de $21,4^{\circ} \mathrm{C}$, precipitação média de $1.278 \mathrm{~mm} / \mathrm{ano}$, ventos predominantes $1^{\mathrm{a}}$ Este e $2^{\mathrm{a}}$ Sudeste, com velocidade média de 2,2 metros/Seg., umidade relativa do ar de $71,5 \%$ e insolação média de 7,7 horas/dia (Tabela 1). Os dados metoerológicos em Piracicaba durante o período experimental encontram-se na Tabela 2. 
Tabela 1. Dados meteorológicos no período 1917-1996. Fonte: DFM/ESALQ-USP, 1997.

Mês Temperatura Média Umidade Relativa Precipitação Insolação $\left({ }^{\circ} \mathrm{C}\right)$

(\%)

(mm) (h/mês)

\begin{tabular}{lllll}
\hline & & & & \\
Jan & 24,3 & 76,0 & 225,8 & 6,4 \\
Fev & 24,6 & 75,0 & 186,4 & 6,6 \\
Mar & 24,0 & 76,0 & 143,1 & 6,8 \\
Abr & 21,8 & 74,0 & 65,4 & 7,5 \\
Mai & 19,1 & 75,0 & 53,5 & 7,3 \\
Jun & 17,6 & 74,0 & 43,4 & 7,1 \\
Jul & 17,3 & 69,0 & 27,7 & 7,9 \\
Ago & 19,1 & 64,0 & 29,7 & 8,2 \\
Set & 20,7 & 64,0 & 61,7 & 6,9 \\
Out & 22,2 & 69,0 & 109,2 & 6,9 \\
Nov & 23,1 & 69,0 & 130,1 & 7,4 \\
Dez & 23,8 & 74,0 & 202,0 & 6,6 \\
& & & & \\
\hline
\end{tabular}


Tabela 2. Dados meteorológicos durante o periodo experimental, no município de Piracicaba. Fonte: DFM/ESALQ-USP, 1997.

\begin{tabular}{llcccc}
\hline Ano & Mês & $\begin{array}{c}\text { Temperatura } \\
\text { Média } \\
\left({ }^{\circ} \mathrm{C}\right)\end{array}$ & $\begin{array}{c}\text { Umidade } \\
\text { Relativa } \\
(\%)\end{array}$ & $\begin{array}{c}\text { Precipitação } \\
(\mathrm{mm})\end{array}$ & $\begin{array}{c}\text { Radiação } \\
\text { Global } \\
(2 \mathrm{cal} / \mathrm{cm} . \mathrm{d})\end{array}$ \\
\hline 1996 & Set & 20,94 & 76,40 & 135,2 & 359,13 \\
1996 & Out & 23,08 & 79,61 & 238,5 & 409,07 \\
1996 & Nov & 23,41 & 79,50 & 212,0 & 407,55 \\
1996 & Dez & 25,20 & 84,77 & 188,3 & 411,52 \\
1997 & Jan & 24,90 & 86,87 & 352,2 & 361,13 \\
1997 & Fev & 24,73 & 79,50 & 87,1 & 380,48 \\
1997 Mar & 23,72 & 73,29 & 73,1 & 356,17 \\
1997 Abr & 21,85 & 73,20 & 22,0 & 304,74 \\
\hline
\end{tabular}

\subsection{Caracterização do local}

A cultura foi estabelecida através do transplante direto das matrizes no campo experimental do Departamento de Produção Vegetal. Segundo VidalTorrado \& Sparovek (1993), o solo desta área é descrito como Terra Roxa Estruturada, Eutrófica, A moderado, textura argilosa sobre muito argilosa. Procedeu-se a análise química antes do plantio, para fins de avaliação da fertilidade, de acordo com Raij et al. (1987), e os resultados encontram-se na Tabela 3. 
Tabela 3. Resultado da Análise de solo da área experimental.

\begin{tabular}{|c|c|c|c|c|c|c|c|c|c|}
\hline P res. & $\begin{array}{r}\text { M.O. } \\
\%\end{array}$ & $\begin{array}{c}\mathrm{pH} \\
\mathrm{CaCl}\end{array}$ & K & $\mathrm{Ca}$ & $\mathbf{M g}$ & $H+A l$ & $s$ & $T$ & V\% \\
\hline 203,5 & 2,82 & 5,65 & 0,80 & 4,90 & 1,18 & 3,08 & 6,9 & 10,0 & 69,1 \\
\hline B & & $\mathrm{Cu}$ & & $\mathrm{Fe}$ & M & & Mo & & $\mathrm{Zn}$ \\
\hline \multicolumn{10}{|c|}{ ppm } \\
\hline 0,40 & & 15,6 & & 51,8 & 106 & & - & & 15,3 \\
\hline
\end{tabular}




\subsection{Cultivares estudadas}

A seguir estão descritas as características e origem das cultivares estudadas neste trabalho.

- Campinas IAC-2712: desenvolvida em 1955 pelo IAC, é o resultado do cruzamento dos clones 'Doner' e 'Tahoe' (Camargo, 1960). Apresenta produção boa e precoce, com frutificação fora da área das folhas, o que facilita a colheita. Os frutos são grandes, de formato cônico-alongados e com pescoço, regularmente firmes, vermelho-rosa brilhante externamente e rosa internamente. $O$ cálice destaca-se facilmente do fruto. Produz de 2 a $5 \mathrm{~kg}$ de frutos $/ \mathrm{m}^{2}$ (Groppo et al., 1997).

- Chandler: foi desenvolvida na Universidade da Califómia, resultado do cruzamento realizado em 1977 entre os clones 'Douglas' e 'Cal. 72.361.105', lançado em 1983 (Faedi et al.,1988). Planta de alto vigor, densidade de folha média, coroa grossa, produção inicial tardia, produtividade alta. O fruto é grande, e de formato cônico-alongado. A epiderme e a polpa são de coloração vermelha-escura, com sabor pouco ácido e aroma ativo (Groppo et al.,1997). Extremamente susceptível a antracnose (Chandler, 1991).

- Dover: desenvolvida na Universidade da Flórida, esta cultivar foi selecionada para a característica de resistência a antracnose nas condições da Flórida, resultado do cruzamento realizado em 1973 entre a cultivar Flórida Belle e o clone 'Fla. 71-189' (Howard \& Albregts, 1980). Planta de vigor médio, coroa grossa, produção inicial precoce, produtividade alta, fruto grande de formato cônico-alongado, epiderme e polpa firme, de coloração vermelho intenso, pouco ácido e de aroma pouco evidenciado (Groppo et al.,1997). 
- IAC Princesa Isabel: desenvolvida pelo engenheiro agrônomo Francisco A. Passos, selecionada do cruzamento realizado em 1981 entre as cultivares Alemanha e IAC Jundiai (Camargo \& Passos, 1993). Planta vigorosa semiereta, assemelhando-se à cultivar Campinas IAC-2712. É precoce e de alta produtividade. Frutos vigorosos, graúdos, cônico-alongados, vermelho-claros e brilhantes, de sabor suave-adocicado e firmes (Groppo et al.,1997).

- Toyonoka: desenvolvida no Japão, resultado do cruzamento entre as cultivares Himiko e Harunoka (Sakai, 1984). Planta ereta, alta, com frutos de formato cônico, firmes, brilhantes, de sabor adocicado e aroma evidenciado. Frutificação sob as folhas. Susceptível a antracnose e ao míldio (Hisatomi²).

. Korona: desenvolvida na Holanda (IUTMageningen) resultado do cruzamento realizado em 1972 entre as cultivares Tamella e Induka (Faedi et al., 1988). Planta produtiva, ereta, folhas abertas, de cor verde escura, inflorescência abundante. Frutos longos, cônicos, epiderme vermelho-escura, polpa vermelha, firme de bom aroma e sabor. Susceptivel a Botrytis cinerea, mildio e Phytophthora infestans (USDA, 1998).

- Pajaro: desenvolvida pela Universidade de Califórnia, lançada em 1979, resultado do cruzamento entre os clones 'Sequóia' e 'Cal. 63.7.101' (Faedi et al.,1988). Frutos longos, simétricos, atrativos e firmes, de alta qualidade para mesa (Bringhurst \& Voth, 1989). Extremamente susceptível a antracnose (Chandler, 1991).

\footnotetext{
${ }^{2}$ HISATOMI, T. (Instituto Agronómico Nacional, Caacupé-Paraguay)
}

Comunicação pessoal, 1998. 


\subsection{Plantio das matrizes e condução}

Para o preparo do solo foram realizadas uma aração e duas gradagens. Posteriormente foram feitos canteiros de $1,20 \mathrm{~m}$ de largura e $0,20 \mathrm{~m}$ de altura, utilizando-se uma encanteiradora mecanizada acoplada a um trator. O espaçamento entre canteiros foi de $0,50 \mathrm{~m}$. Não foi efetuada adubação de plantio devido ao alto teor de nutrientes revelados na análise de solo do local. A adubação de cobertura foi realizada 30 dias após o plantio, empregando-se $10 \mathrm{~g}$ de uréia por matriz.

O plantio foi realizado no dia $28 / 10 / 1996$, sendo efetuado no período do final da tarde. O espaçamento adotado foi de $1,2 \times 1,0 \mathrm{~m}$, sendo 1,2 $\mathrm{m}$ a largura dos canteiros e 1,0 m a distância entre as plantas matrizes plantadas no centro dos canteiros.

Logo após o plantio foi realizada uma irrigação por aspersão. Durante as duas primeiras semanas a irrigação foi diária. Após o pegamento das matrizes e o estabelecimento da cultura no campo, a irrigação foi realizada em intervalos maiores ( 2 a 3 vezes por semana).

Os tratos culturais constaram do controle de pragas e doenças conforme a necessidade. Para o controle de plantas daninhas foram realizadas capinas manuais, com intervalo de aproximadamente 15 dias, durante todo o ciclo da cultura.

\subsection{Tratamentos}

Os fatores em estudo foram:

A- Cultivares

Foram estudadas sete cultivares de morangueiro, sendo duas desenvolvidas no Brasil: 'Campinas IAC-2712', 'IAC Princesa Isabel'; três nos Estados Unidos: 'Chandler', 'Dover', 'Pajaro'; uma no Japão: 'Toyonoka' e uma na Holanda: 'Korona'. 
B- Épocas de coleta das mudas

Os periodos de coleta das mudas de estolhos foram: $E_{1}=14 / 03 / 97$ e $E_{2}=$ 15/04/97.

\subsection{Delineamento experimental}

Utilizou-se o delineamento em blocos completamente casualizados, em esquema fatorial $7 \times 2$, com sete cultivares e duas épocas de coleta, com quatro repetições, perfazendo 56 parcelas experimentais. Foram utilizadas duas plantas matrizes por parcela.

A parcela experimental tinha $2,40 \mathrm{~m}^{2}(1,20 \times 2,00) \mathrm{m}$.

\subsection{Análise estatística}

Os dados obtidos foram submetidos à análise de variância, através do Sistema SANEST, aplicando-se o teste $\mathrm{F}$ e procedendo-se o detalhamento da análise pelo teste de Tukey ao nível de $5 \%$ de probabilidade.

\subsection{Avaliação}

As seguintes variáveis foram analisadas:

a. Total de mudas de estolhos produzidas por metro quadrado: foram coletadas e contadas as mudas de estolhos na área de $1 \mathrm{~m}^{2}$ da parcela. A coleta foi realizada com o auxilio de um quadrado de madeira de dimensão de $1 \times 1 \mathrm{~m}$;

b. Classificação das mudas de estolhos: após a coleta, as mudas foram classificadas em quatro categorias, conforme o diâmetro da coroa, altura da parte aérea e número de folhas. Na Tabela 4 e Figura 1 estão representados os parâmetros tomados para a avaliação das mudas coletadas. 
Tabela 4. Parâmetros e categorias adotadas para a avaliação das mudas coletadas.

\begin{tabular}{lcccc}
\hline Parâmetros & \multicolumn{4}{c}{ Categorias } \\
\cline { 2 - 5 } & Extra & Primeira & Segunda & Descarte $^{*}$ \\
\hline Diâmetro da coroa $(\mathrm{mm})$ & $\geq 12$ & $12-9$ & $9-5$ & $<5$ \\
Altura da parte aérea & $\geq 150$ & $150-130$ & $130-70$ & $<70$ \\
(mm) & & & & \\
Número de folhas & $\geq 7$ & $7-5$ & $5-2$ & $<2$ \\
\hline
\end{tabular}

* Sem raízes e pequeno desenvolvimento das mudas de estolho 

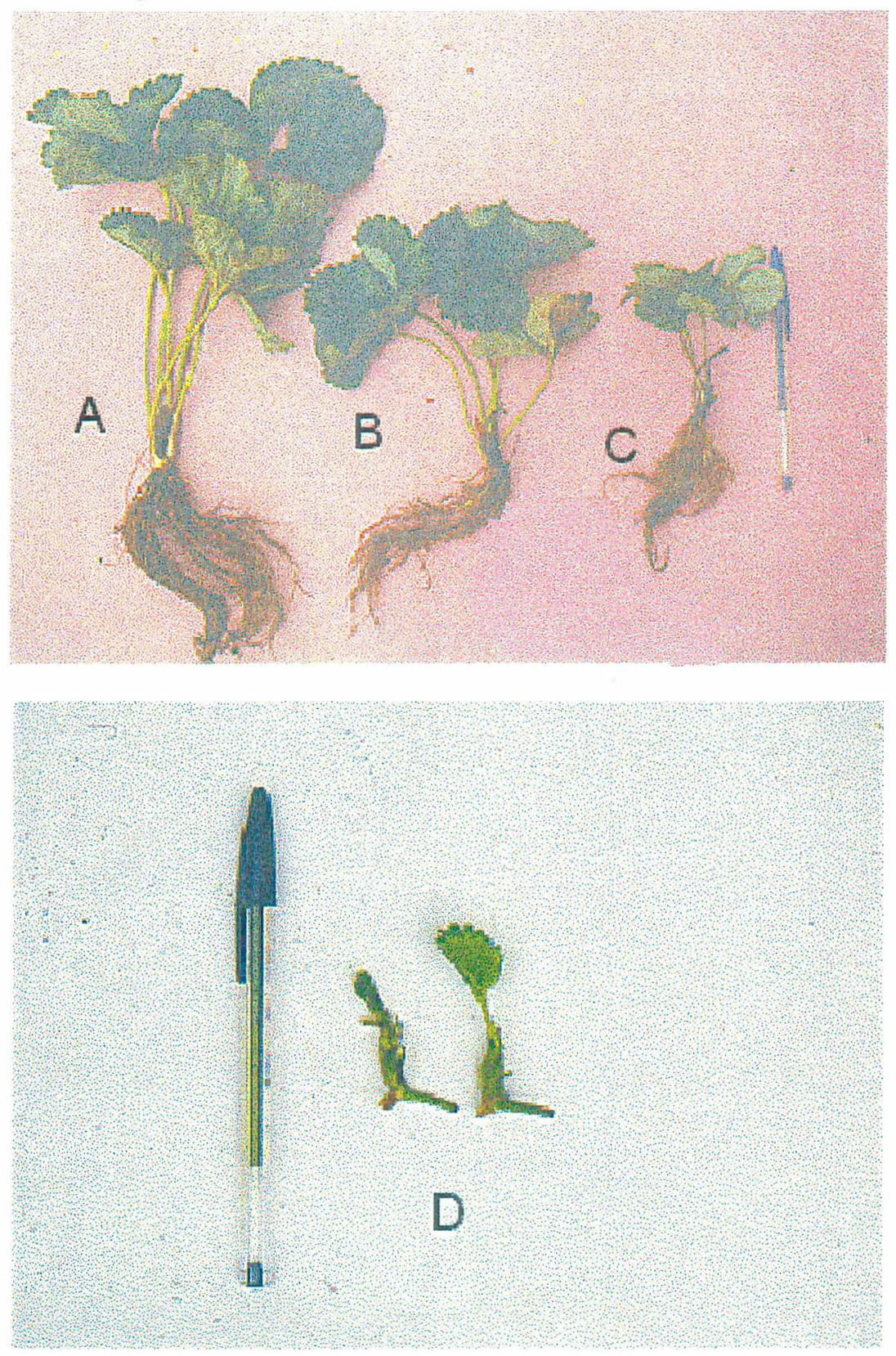

Figura 1. Categoria de mudas de morangueiro avaliadas no experimento: $A=$ Extra; $B=$ Primeira; $C=$ Segunda; $D=$ Descarte. 


\section{RESULTADOS E DISCUSSÃO}

Na Tabela 5 está apresentado o análise de variância para os efeitos dos tratamentos sobre as variáveis analisadas no experimento.

Observa-se que para a variável tipo de muda produzida houve influência significativa da época e da cultivar nas mudas das categorias Extra, Primeira e Descarte. Para a categoria Segunda houve influência apenas da época de coleta. Para todas as categorias não houve interação entre época de coleta e cultivar.

Quanto à variável número de mudas de estolhos produzidas por $\mathrm{m}^{2}$, não foi constatado efeito do fator época de coleta, entretanto, para o fator cultivar, houve efeito altamente significativo. A interação época de coleta e cultivar também não foi significativa para esta variável.

Em vista de não ter havido efeito da interação época de coleta $x$ cultivar, os fatores são analisados de forma independente. 
Tabela 5. Análise de Variância e teste F para os efeitos dos tratamentos sobre as variáveis analisadas (Mudas das categorias Extra, Primeira, Segunda e Descarte e número total de mudas de estolhos produzidas $/ \mathrm{m}^{2}$ ). Piracicaba - SP. 1997.

\begin{tabular}{|c|c|c|c|c|c|c|}
\hline \multirow{2}{*}{$\begin{array}{l}\text { Causas da } \\
\text { Variação }\end{array}$} & \multirow[t]{2}{*}{ G.L. } & \multicolumn{5}{|c|}{ Quadrados médios e significância do teste $F^{1}$} \\
\hline & & Extra & Primeira & Segunda & Descarte & $\begin{array}{c}\text { Total de } \\
\text { estolhos } / \mathrm{m}^{2}\end{array}$ \\
\hline $\begin{array}{l}\text { Ėpoca de } \\
\text { coleta ( E) }\end{array}$ & 1 & $412,937^{\star \star}$ & $458,535^{\star \star}$ & $731,114^{\star \star}$ & $4521,337^{\star \star}$ & $204,446^{\text {n.s. }}$ \\
\hline Cultivares ( C) & & $160,907^{\star \star}$ & $63,070^{\star \star}$ & $47,020^{\text {n.s. }}$ & $268,451^{\star \star}$ & $55327,666^{\star \star}$ \\
\hline Bloco & 3 & $47,675^{\text {n.s. }}$ & $73,828^{\star \star}$ & $54,751^{\text {n.s. }}$ & $299,222^{\star \star}$ & $372,494^{\text {n.s. }}$ \\
\hline$E \times C$ & 6 & $31,768^{\text {n.s. }}$ & $24,339^{\text {n.s. }}$ & $37,535^{\text {n.s. }}$ & $11,686^{\text {n.s. }}$ & $4131,488^{\text {n.s. }}$ \\
\hline Resíduo & 39 & 39,320 & 16,996 & 31,527 & 52,014 & 2461,237 \\
\hline C.V. ( \% & & 30,23 & 16,79 & 16,74 & 19,90 & 42,27 \\
\hline
\end{tabular}

Pela Tabela 6 e Figura 2 verifica-se que as cultivares Campinas e Dover apresentaram maior produção de mudas de estolhos $/ \mathrm{m}^{2}$ do que as demais cultivares, cerca de $50 \%$ maior, em média. Esses resultados estão parcialmente de acordo com as observações de Betti ${ }^{3}$. Este pesquizador afirmou que as cultivares Campinas, Dover e Chandler apresentam alta taxa de produção de mudas de estolhos, o que não ocorre para a cultivar Toyonoka, considerada de baixa taxa de multiplicação.

As diferenças na produção de mudas das cultivares testadas está ligada, provavelmente, à herança genética para esta característica.

${ }^{3}$ BETTI, J. A. (Instituto Agronômico de Campinas - Centro de Fitossanidade) Comunicação pessoal, 1998. 
Foi verificado ainda que, para as condições do experimento, a cultivar Chandler apresentou produção de mudas inferior a Dover e Campinas, o que não permite classificá-la como uma cultivar de alta taxa de multiplicação.

Tabela 6. Número total de mudas de estolhos $/ \mathrm{m}^{2}$ produzidas pelas diferentes cultivares de morangueiro. Piracicaba, 1997.

\begin{tabular}{lc}
\hline Cultivar & Mudas de estolhos $/ \mathrm{m}^{2}$ \\
\hline P. Isabel & $170,37 \mathrm{~b}$ \\
Toyonoka & $150,25 \mathrm{~b}$ \\
Pajaro & $110,12 \mathrm{~b}$ \\
Chandler & $177,00 \mathrm{~b}$ \\
Korona & $183,25 \mathrm{~b}$ \\
Campinas & $301,37 \mathrm{a}$ \\
Dover & $338,25 \mathrm{a}$ \\
\hline C.V. (\%) & 24,27
\end{tabular}

Médias seguidas de mesma letra na coluna não diferem entre si pelo teste de Tukey ao nível de $5 \%$ de probabilidade. 


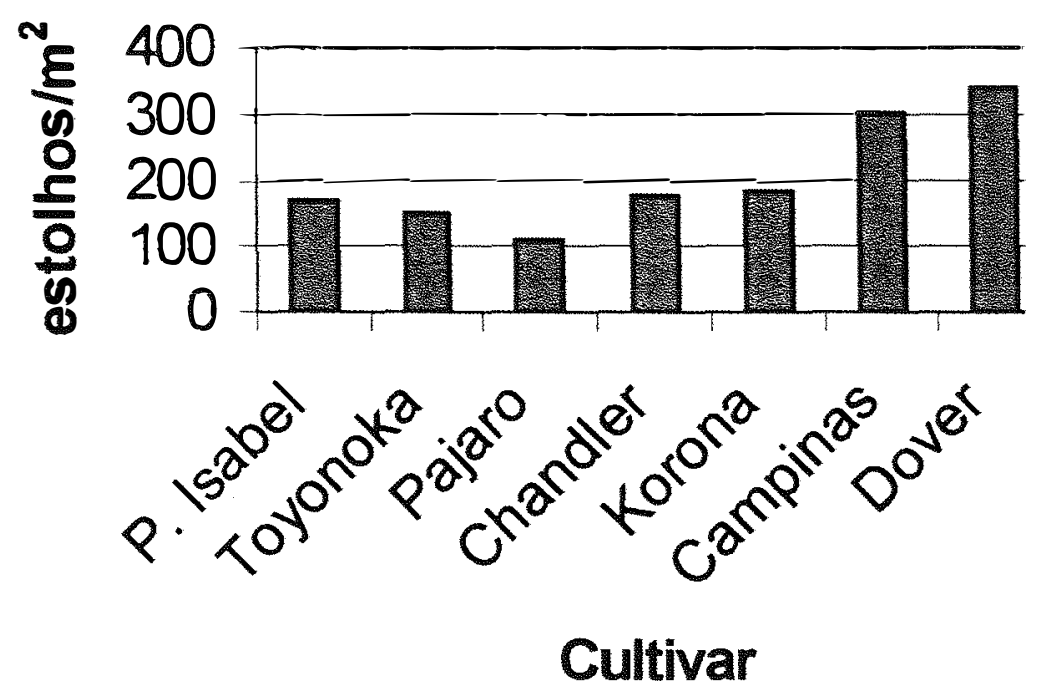

Figura 2: Número total de mudas de estolhos $/ \mathrm{m}^{2}$ produzidas pelas diferentes cultivares de morangueiro. Piracicaba, 1997. 


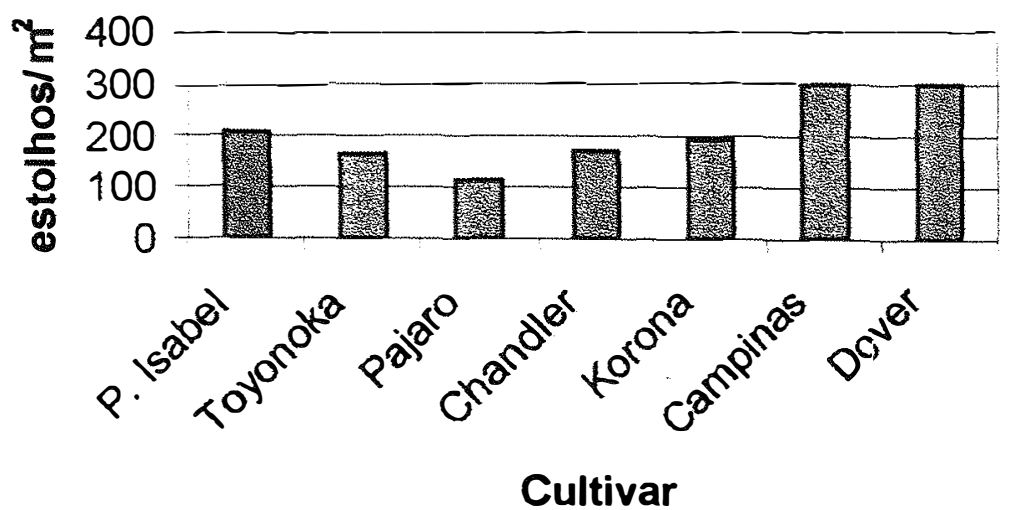

Figura 3. Número total de mudas de estolhos produzidas por metro quadrado pelas diferentes cultivares de morangueiro na primeira época de coleta (14/03). Piracicaba, 1997.

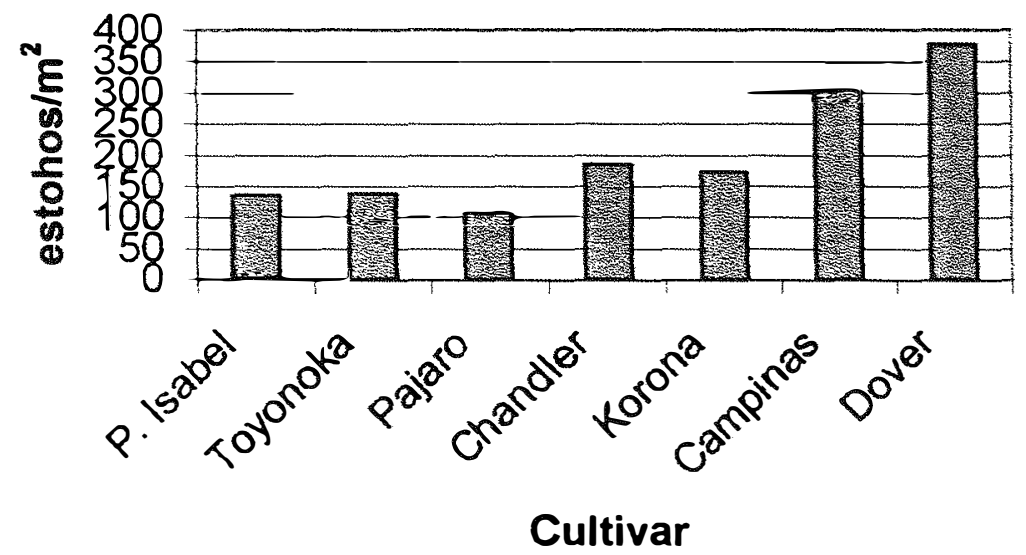

Figura 4. Número total de mudas de estolhos produzidas por metro quadrado pelas diferentes cultivares de morangueiro na segunda época de coleta (14/04). Piracicaba, 1997. 
Os efeitos das diferentes cultivares sobre a percentagem de mudas classificadas em diferentes categorias encontram-se na Tabela 7. Observou-se que, na categoria Extra, a cultivar Princesa Isabel apresentou a maior percentagem (20\%), superando estatisticamente as cultivares Campinas $(7 \%)$, Dover (7\%), e não deferindo das demais cultivares. Para a categoria Primeira, os maiores percentuais foram encontrados para Toyonoka (24\%) e Princesa Isabel (22\%), as quais superaram estatisticamente as cultivares Dover (15\%) e Campinas (13\%). Na categoria Segunda não foi observada diferença estatistica entre as cultivares.

Em relação ao percentual de mudas descartadas, observa-se que as cultivares Campinas e Dover apresentaram as maiores percentuais (48\% e $45 \%$, respectivamente). A cultivar Campinas apresentou Descarte significativamente superior ao observado para as cultivares Princesa Isabel e Toyonoka, enquanto que a cultivar Dover apresentou descarte superior apenas a Toyonoka.

Comparando-se a Tabela 7 com a Tabela 6, observa-se que, embora as cultivares Campinas e Dover tenham produzido maior quantidade de mudas de estolhos por metro quadrado, houve uma tendência das mudas apresentarem menor qualidade, traduzida pelo alto percentual de mudas de Descarte (quase $50 \%$ ) e baixo percentual de mudas classificadas como Extra $(7 \%)$. Este comportamento também foi verificado por Rodríguez (1997) quando observou que a produção em quantidade elevada de mudas $/ \mathrm{m}^{2}$, compromete a qualidade das mesmas, pois compromete o desenvolvimento da coroa. 
Tabela 7. Porcentagens de mudas de estolhos classificadas nas diferentes categorias e produzidas pelas cultivares de morangueiro estudadas. Piracicaba, 1997.

\begin{tabular}{|c|c|c|c|c|}
\hline \multirow[b]{2}{*}{ Cultivar } & \multicolumn{4}{|c|}{ Categoria $^{7}$} \\
\hline & Extra & Primeiro & Segunda & Descarte \\
\hline & \multicolumn{4}{|c|}{ 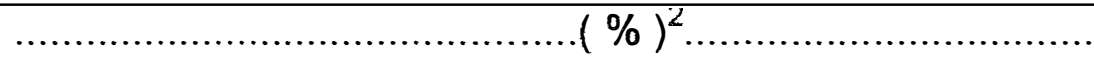 } \\
\hline P. Isabel & $20 a$ & $22 a b$ & $30 a$ & $28 \mathrm{bc}$ \\
\hline Toyonoka & $18 a b$ & $24 a$ & $36 a$ & 22 \\
\hline Pajaro & $16 a b$ & $17 a b c$ & $26 a$ & $41 a b$ \\
\hline Chandler & $10 a b$ & $18 \mathrm{abc}$ & $34 a$ & $38 \mathrm{abc}$ \\
\hline Korona & $18 a b$ & $17 a b c$ & $29 a$ & $36 \mathrm{abc}$ \\
\hline Campinas & $7 b$ & $13 \mathrm{c}$ & $32 a$ & $48 a$ \\
\hline Dover & $7 b$ & $15 \mathrm{bc}$ & $33 a$ & $45 a b$ \\
\hline C.V.( \%) & 30,23 & 16,79 & 16,74 & 19,90 \\
\hline \multicolumn{5}{|c|}{$\begin{array}{l}\text { Médias seguidas de mesma letra na coluna não diferem entre si pelo teste de Tukey ao nível d } \\
5 \% \text { de probabilidade. } \\
\text { Extra: diâmetro da coroa maior ou igual } 12 \mathrm{~mm} \text {, altura da parte aérea maior o igual } 150 \mathrm{~mm} \\
\text { número de folhas maior o igual } 7 \text { unidades; Primeira: diâmetro da coroa entre } 12-9 \mathrm{~mm} \text {, altur } \\
\text { da parte aérea entre } 150-130 \mathrm{~mm} \text { e entre } 7 \text { a } 5 \text { folhas; Segunda: entre } 9-5 \mathrm{~mm} \text {, altura d } \\
\text { parte aérea entre } 130-70 \mathrm{~mm} \text { e entre } 5-2 \text { folhas; e Descarte, diâmetro da coroa menor a } \\
\text { mm, altura da parte aérea menor a } 70 \mathrm{~mm} \text {, menor a } 2 \text { folhas, com ausência de raizes } \\
\text { pequeno desenvolvimento do estolho. } \\
\text { Valores aproximados }\end{array}$} \\
\hline
\end{tabular}

$\mathrm{Na}$ Tabela 8 encontram-se os resultados obtidos para o efeito da época de coleta das mudas sobre a classificação das mudas e número total de mudas de estolhos produzidos por metro quadrado.

Conforme observado, não houve efeito da época de coleta sobre o número de mudas produzidos por metro quadrado, enquanto que para a classificação observou-se que a segunda época (15/04/97) apresentou mudas de melhor qualidade do que a primeira época (14/03/97), o que foi traduzido 
pelo maior percentual de mudas classificadas como Extra, Primeira e Segunda, e menor percentual de mudas classificadas como Descarte.

Este resultado ocorre em função de que as mudas da segunda época tiveram mais tempo para se desenvolver, cerca de 30 dias a mais do que as mudas da primeira época.

Cabe ressaltar que, embora na primeira época as mudas tenham atingido qualidade inferior à segunda época, esta produção é importante, uma vez que os produtores buscam maior precocidade de produção de frutos. Tem sido verificado que os maiores valores obtidos na comercialização de morango ocorre nos meses de junho a agosto (Agrianual, 1999). As mudas plantadas na segunda época (15/04/97) iniciaram a produção no final de junho, enquanto que as plantadas na primeira época (14/03/97) iniciaram a produção no final de maio, o que poderia tornar mais rentável ao produtor de frutas, uma vez que a safra seria antecipada em relação ao pico de produção e comercialização. 
Tabela 8. Porcentagens de mudas de estolhos classificadas nas diferentes categorias e coletadas em duas diferentes épocas. Piracicaba, 1997.

\begin{tabular}{|c|c|c|c|c|c|}
\hline \multirow{2}{*}{$\begin{array}{l}\text { Época de } \\
\text { coleta }\end{array}$} & \multicolumn{4}{|c|}{ Categoria } & \multirow{2}{*}{$\begin{array}{l}\text { Número total } \\
\text { de mudas }\end{array}$} \\
\hline & Extra & Primeira & Segunda & Descarte & \\
\hline & & 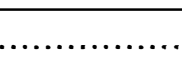 & $\overline{1}^{2}$ & & Estolhos $/ \mathrm{m}^{2}$ \\
\hline $14 / 03 / 97$ & $10 \mathrm{~b}$ & $14 \mathrm{~b}$ & $25 \mathrm{~b}$ & $51 \mathrm{~b}$ & $202,46 a$ \\
\hline $15 / 04 / 97$ & $18 a$ & $22 a$ & $37 a$ & $23 a$ & $206,28 a$ \\
\hline C.V.( \%) & 30,23 & 16,79 & 16,74 & 19,90 & 24,27 \\
\hline
\end{tabular}

Médias seguidas de mesma letra na coluna não diferem entre si pelo teste de Tukey ao nível de $5 \%$ de probabilidade.

${ }^{1}$ Extra: diâmetro da coroa maior ou igual $12 \mathrm{~mm}$, altura da parte aérea maior o igual $150 \mathrm{~mm}$, número de folhas maior o igual 7 unidades; Primeira: diâmetro da coroa entre $12-9 \mathrm{~mm}$, altura da parte aérea entre $150-130 \mathrm{~mm}$ e entre 7 a 5 folhas; Segunda: entre $9-5 \mathrm{~mm}$, altura da parte aérea entre 130 - $70 \mathrm{~mm}$ e entre 5 - 2 folhas; e Descarte, diâmetro da coroa menor a 5 $\mathrm{mm}$, altura da parte aérea menor a $70 \mathrm{~mm}$, menor a 2 folhas, com ausência de raízes e pequeno desenvolvimento do estolho.

${ }^{2}$ Valores aproximados 


\section{CONSIDERAÇÕES GERAIS}

A classificação e a seleção das mudas de estolhos por tamanho é feita de maneira empírica por parte dos produtores. Estes normalmente não utilizam padrões definido de tamanho de muda, devido à inexistência de portaria ou legislação de frutos, deve-se atentar para uma melhor organização da sua produção.

Desta forma, a padronização e a classificação das mudas produzidas e ofertadas para produção, beneficiaria tanto o produtor de mudas como 0 produtor de frutos. 


\section{CONCLUSŌES}

No estudo das diferentes cultivares de morangueiro e épocas de coleta de mudas de estolhos, as seguintes conclusões podem ser feitas para as condições de Piracicaba - SP:

- existem diferenças quanto a quantidade de mudas de morangueiro produzidos por metro quadrado, de acordo com o cultivar. As cultivares Dover e Campinas produzem maior quantidade de mudas do que as cultivares Korona, Chandler, Princesa Isabel, Toyonoka e Pajaro, independente da época de coleta;

- A época de coleta mais tardia proporciona a obtenção de mudas de melhor qualidade. 


\section{REFERÊNCIA BIBLIOGRÁFICA}

AGRIANUAL 99 Anuário da Agricultura Brasileira FNP Consultoria \& Comercio. Mendes \& Scotoni . 1999. 521 p.

alvarez, e.; Amarilla, e.; martínez, M.; VAliente, A. Producción de mudas de frutilla con plantas madres libres de virus. Caacupé: Ministerio de Agricultura y Ganaderia, 1998. 28p.

ANUARIO IEA - 1996. São Paulo: IEA, 1997. 134p.

BRINGHURST, R.S.; VOTH, V. California strawberry cultivars. Fruit Varieties Joumal, v.43, n.1, p. 12-19, 1989.

CAMARGO, L. de S. Instruções para a cultura de morangueiro. 6 ed. Campinas: IAC, Instituto Agronômico, 32 p. 1973 (IAC. Boletim, 29).

CAMARGO, L. de S. Novas variedades de morangueiro no Estado de São Paulo. Piracicaba, 1960. 48p. Tese (Doutorado) - Escola Superior de Agricultura "Luiz de Queiroz", Universidade de São Paulo

CAMARGO, L. de S.; PASOS, F.A. Morango. In: FURLANI, A.M.C.; VIEGAS, G.P. (Ed.). O melhoramento de plantas no Instituto Agronómico. Campinas: Instituto Agronômico, 1993. v.1, cap. 11, p. 411-432. 
CÁRDENAS-NAVARRO, R.; MANZO-GONZÁLEZ, A.; MURATALLA-LÚA, A. Propagación de siete cultivares de Fresa (Fragaria $x$ ananassa Duch.) en el Valenciano, Ixtlan de los Hervores, Michoacan, México. Revista Chapingo, v. 16, n.78, p.100-113, 1992.

CHANDLER, C. K.; STOFFELLA, P.J.; ALBREGTS, E.E.; HOWARD, C.M. Stability of strawberry genotypes in the annual hill cultured system. HortScience, v.22, n.11, p.1409-1411, 1991.

COOMBE, B.G. The development of fleshy fruits. Annual Review of Plant Physiology, v.27, p.507-528, 1976.

CRONQUIST, A. An integrated system of classification of flowering plants. New York: Columbia University Press, 1981. $1262 \mathrm{p}$.

CUNHA. R.J.P. Comportamento de híbridos de morangueiro (Fragaria spp.), na região de Botucatu-SP. Piracicaba, 1976. 110p. Dissertação (Mestrado) Escola Superior de Agricultura "Luiz de Queiroz", Universidade de São Paulo.

DENNIS JR., F.G.; LIPECKI, J.; KIANG, C. Effects of photoperiod and other factors upon flowering and runner development of three strawberry cultivars. Journal of the American Society for Horticultural Science, v.95, n.6, p.750-754, 1970.

ENGLER, A. Syllabus der pflanzenfamiliem. 12 ed. Berlim: Gebruder Borntraeger, 1954. 367p. 
FAEDI, W.; ARCUTI, P.; LOVATTI, L.; RECUPERO, S.; TURCI, P. Monografia di cultivar di fragola. Roma: Istituto Sperimentale per la Frutticultura, 1988. 36p. (ISF. Publicações, 296)

FAO. PRODUCTION YEARBOOK, Roma: FAO, v.50, p.169, 1997.

FILGUEIRA, F.A.R. Manual de olericultura : cultura e comercialização de hortaliças. 2 ed. São Paulo: Agronômica Ceres, 1982. 2v. 357 p.

GALLETTA, G.J.; BRINGHURTS, R.S. Strawberrry management. In: GALLETTA, G.J.; HIMELRICK, D.G. (Ed.). Small fruit crop management. New Jersey: Prentice Hall, 1990. cap.3, p.83-156.

GROPPO, G.A.; TESSARIOLI NETO, J. A cultura do morangueiro. Campinas: CATI,1991. 16 p. (CATI. Boletim Técnico, 201)

GROPPO, G.A.; TESSARIOLI NETO, J.; BLANCO, M.C.S.G. . A cultura do morangueiro. 2 ed. Campinas: CATI, 1997. 27 p. (CATI. Boletim Técnico, 201)

HERSKETH, J.L.; EATON, G.W.; BAUMANN, T.E. Strawberry runnering and leaf size depend on plant spacing. Fruit Varieties Journal, v.44, n.1, p.26$31,1990$.

HOWARD, C.M.; ALBREGTS, E.E. 'Dover' strawberry. HortScience, v.15, n.4, p.540, 1980.

INFORZATO, R.; CAMARGO, L.S. Sistema radicular do morangueiro (Fragaria híbridos) em duas fases do ciclo vegetativo. Bragantia, v.32, p.185-191, 1973. 
IUCHI, T. Crescimento da planta e do fruto do morangueiro (Fragaria $x$ ananassa Duch.) em diferentes regimens hídricos. Viçosa, 1993. 187p. Tese (Doutorado) Universidade Federal de Viçosa.

LARSON, K.D. Strawberry. In: SACHAFFER, B.; ANDERSEN, P.C. (Ed.) Handbook of enviromental physiology of fruit crops. Boca Raton: CRC Press, 1994. cap.10, p.271-297.

MIQUELÃO, R.M.; ZAMBON, F.R.; KOEHLER, H.S.; GUSI, L.C. Influencia de três fontes de adubação em cobertura na emissão de estolões em morangueiro. SOB Informa, v.13, n. 1, p. 33-35. 1994

PADOVANI, M.l. Morango: o delicado e saboroso fruto da integração dos povos. São Paulo: Icone, 1991. $68 \mathrm{p}$.

PASSOS, F.A. Desenvolvimento de cultivares de morangueiro. In : SIMPÓSIO SOBRE A CULTURA DO MORANGUEIRO. 1., 1986. Anais. Campinas: CATI, 1991. p. 1-14.

PASSOS, F.A.; TRANI, P.E.; BETTI, J.A.; TANAKA, M.A.S. Morango. In: INSTITUTO AGRONÔMICO DE CAMPINAS. Instruções agrícolas para o Estado de São Paulo. 6.ed. Campinas, 1998. p.222-225. (IAC. Boletim, 200)

QUEIROZ-VOLTAN, R.B.; JUNG-MENDAÇOLLI, S.L.; PASSOS, F.A.; SANTOS, R.R. Caracterização botânica de cultivares de morangueiro. Bragantia, v.55, n.1, p.29-44, 1996. 
RAIJ, B. VAN; QUAGGIO, J.A.; CANTARELLA, H.; FERREIRA, M.E.; LOPES, A.S.; BATAGLIA, O.C. Análise química do solo para fins de fertilidade. Campinas: Fundação Cargill, 1987. 170p.

REBELO, J.A.; BALARDIN, R. S. A cultura do morangueiro. 2. ed., Florianópolis: EPAGRI, 1993, 40 p. (Boletim Técnico, 46)

RICE JR, R.P. Effects of cultivar and enviromental interactions on runner production, fruit yield, and harvest timing of strawberry (Fragaria $\mathrm{x}$ ananassa Duch.) in Zimbabwe. Acta Horticulturae, n. 279, p. 327-332, 1990.

RODRÍGUEZ, J.P. Manejo del Cultivo. IN: TORCHELLI, J.C.; FERREYRA, A. (Ed.) Producción de Frutilla: Proyecto de diversificación produtiva. Marzo, 1997. (Serie B, n. 6)

SAKAI, K. New summer crop cultivars (II) - new cultivars registered by the Ministry of Agriculture, forestry and Fishieries in 1983. Strawberry. Japanese Journal of Breeding, v.34, n.1, p.123-124, 1984. I Resumo em CAB Abstracts on CD-ROM, 184-86/

SANTOS, A.M. A cultura do morango. Brasília: EMBRAPA - SPI, 1993. 35p. (Coleção Plantar, 7)

SECRETARIA DE AGRICULTURA E ABASTECIMENTO DE SÃO PAULO. Programa paulista de apoio à cultura do morango. São Paulo, 1996. 13p.

STEINBERG, E. Morango. São Paulo: Nobel, 1988. 54p. (Campo \& Cidade, 20) 
TÜREMIS, N.; KASKA, N.; ÇÖMLEKÇIOGLA, N. Comparison of runner plant obtained by conventional and meristem cultured methods. Acta Horticulturae, n.439, p. 359-362, 1997.

USDA, ARS, National Genetic Resources Program. Germplasm Resources Information Network - (GRIN). (Online Database) National Resources Laboratory, Beltsville, Maryland. Available: umw.ars-grin.gov/cgibin/npgs/html.pl 1998.

VIDAL-TORRADO, P.; SPAROVEK, G. Mapa pedológico detalhado do Campus "Luiz de Queiroz", ESALQ/USP. Piracicaba: ESALQ, 1993 (Escala 1:10.000).

WEBB, R.A.;WHITE, B.A. The effect of rooting date of flower production in the strawberry. Journal Horticultural Science, v. 46, p.413-423, 1971. 


\section{APÊNDICE}


Apêndice 1. Diâmetro médio $(\mathrm{mm})$ do caule das mudas de estolhos de morangueiro classificadas nas categorias Extra, Primeira e Segunda. ESALQ/USP, Piracicaba, 1997.

\begin{tabular}{cccc}
\hline Cultivares & Extra & Primeira & Segunda \\
\hline Princesa Isabel & 13,32 & 10,56 & 7,28 \\
Toyonoka & 12,11 & 9,87 & 7,23 \\
Pajaro & 13,15 & 9,80 & 7,20 \\
Chandler & 13,81 & 10,12 & 7,50 \\
Korona & 12,76 & 10,15 & 7,25 \\
Campinas & 13,48 & 9.76 & 7,31 \\
Dover & 15,54 & 10,05 & 7,41 \\
\hline
\end{tabular}


Apêndice 2. Altura média $(\mathrm{cm})$ da parte aérea das mudas de estolhos de morangueiro classificadas nas categorias Extra, Primeira e Segunda. ESALQ/USP, Piracicaba, 1997.

\begin{tabular}{cccc}
\hline Cultivares & Extra & Primeira & Segunda \\
\hline Princesa Isabel & 16,16 & 13,99 & 10,60 \\
Toyonoka & 15,81 & 13,58 & 10,75 \\
Pajaro & 16,19 & 13,94 & 11,25 \\
Chandler & 17,84 & 14,71 & 10,85 \\
Korona & 15,46 & 14,17 & 10,19 \\
Campinas & 20,62 & 14,72 & 10,73 \\
Dover & 16,80 & 14,44 & 11,01 \\
\hline
\end{tabular}


Apêndice 3. Média do número de folhas das mudas de estolhos de morangueiro classificadas nas categorias Extra, Primeira e Segunda. ESALQ/USP, Piracicaba-SP, 1997.

\begin{tabular}{cccc}
\hline Cultivares & Extra & Primeira & Segunda \\
\hline Princesa Isabel & 7,43 & 6,27 & 4,37 \\
Toyonoka & 6,56 & 5,79 & 4,02 \\
Pajaro & 7,31 & 5,47 & 4,24 \\
Chandler & 7,79 & 5,72 & 4,66 \\
Korona & 7,35 & 5,87 & 4,49 \\
Campinas & 7,45 & 5,27 & 4,20 \\
Dover & 7,39 & 6,12 & 4,52 \\
\hline
\end{tabular}


Apêndice 4. Número médio de mudas de estolhos produzidas por $\mathrm{m}^{2}$ das cultivares estudadas e classificadas em diferentes categorias, coletadas em 14/03/97. Piracicaba, 1997.

\begin{tabular}{|c|c|c|c|c|c|}
\hline \multirow[b]{2}{*}{ Cultivar } & \multicolumn{4}{|c|}{ Categoria $^{\top}$} & \multirow{2}{*}{$\begin{array}{c}\text { Número Total } \\
\text { de mudas de } \\
\text { estolhos } / \mathrm{m}^{2}\end{array}$} \\
\hline & Extra & Primeira & Segunda & Descarte & \\
\hline P. Isabel & 26,25 & 31,5 & 61 & 86,75 & 205,5 \\
\hline Toyonoka & 17,5 & 46,25 & 48 & 51,5 & 163,25 \\
\hline Pajaro & 14,75 & 14 & 21,5 & 63,75 & 114 \\
\hline Chandler & 13,25 & 20,25 & 46 & 90 & 169,5 \\
\hline Korona & 20 & 25,75 & 48,25 & 99,5 & 193,5 \\
\hline Campinas & 18,75 & 27,5 & 67,5 & 185,5 & 299,25 \\
\hline Dover & 17,5 & 29 & 75,75 & 176,75 & 299 \\
\hline
\end{tabular}


Apêndice 5. Número médio de mudas de estolhos produzidas por $\mathrm{m}^{2}$ das cultivares estudadas e classificadas em diferentes categorias, coletadas em 15/04/97. Piracicaba, 1997.

\begin{tabular}{|c|c|c|c|c|c|}
\hline \multirow[b]{2}{*}{ Cultivar } & \multicolumn{4}{|c|}{ Categoria $^{1}$} & \multirow{2}{*}{$\begin{array}{l}\text { Número Tota } \\
\text { de mudas de } \\
\text { estolhos } / \mathrm{m}^{2}\end{array}$} \\
\hline & Extra & Primeira & Segunda & Descarte & \\
\hline P. Isabel & 33,5 & 37 & 42 & 22,75 & 135,25 \\
\hline Toyonoka & 29,5 & 29,75 & 60,25 & 17,75 & 137,25 \\
\hline Pajaro & 25,25 & 21,5 & 32,5 & 27 & 106,25 \\
\hline Chandler & 20,5 & 45 & 78 & 41 & 184,5 \\
\hline Korona & 38,25 & 33,75 & 56 & 45 & 173 \\
\hline Campinas & 23,5 & 49,75 & 131 & 99,5 & 303,5 \\
\hline Dover & 30 & 79,75 & 156,5 & 111,25 & 377,5 \\
\hline
\end{tabular}

${ }^{\top}$ Extra: diâmetro da coroa maior ou igual $12 \mathrm{~mm}$, altura da parte aérea maior o igual $150 \mathrm{~mm}$, número de folhas maior o igual 7 unidades; Primeira: diâmetro da coroa entre $12-9 \mathrm{~mm}$, altura da parte aérea entre $150-130 \mathrm{~mm}$ e entre 7 a 5 folhas; Segunda: entre $9-5 \mathrm{~mm}$, altura da parte aérea entre 130 - $70 \mathrm{~mm}$ e entre 5 - 2 folhas; e Descarte, diâmetro da coroa menor a 5 $\mathrm{mm}$, altura da parte aérea menor a $70 \mathrm{~mm}$, menor a 2 folhas, com ausência de raízes e pequeno desenvolvimento do estolho. 